\title{
PROBLEMATICS OF RELIABILITY OF ROAD ROLLERS
}

\author{
Michat STAWOWIAK, Mariusz KUCZAJ \\ Silesian University of Technology
}

\begin{abstract}
:
This article refers to the reliability of road rollers used in a selected roadworks company. Information on the method of road rollers service and how the service affects the reliability of these rollers is presented. Attention was paid to the process of the implemented maintenance plan with regard to the machine's operational time. The reliability of road rollers was analyzed by determining and interpreting readiness coefficients.
\end{abstract}

Key words: exploitation, reliability, operation process, road roller

\section{INTRODUCTION}

Exploitation of machines for works related to road construction is associated with undertaking a number of organizational, technical and economic activities [7].

The individual persons who have at their disposal various technical means (machines and devices) are responsible for conducting these activities. The technical operation of road machines is primarily based on their rational use, and in the other on maintaining them in a condition that guarantees the proper course of the operational process.

The most desirable and at the same time essential stage of operation is use. In the process of using machines and devices, a number of links forming use chains with a common purpose of action [8] are combined. However, in order for the machine to be used it is necessary to carry out a number of technical activities. They include: inspections, exchanges, repairs, diagnoses, calibrations, assembly, disassembly, etc. The operational repertoire consists of at least two states: the state of use (called short-term use) and the state of service (called service) [7].

In managing the operation of machines, management of their maintenance takes an important place. It is important to manage the maintenance in such a way that the expenditures incurred for this contribute to reducing the losses resulting from unforeseen stoppages. On the other hand, it should be remembered that the operation of machines does not cause them excessive layovers, which results in losses related to the inability to use them.

Road rollers, like all other machines, are subject to a wear process. The wear of the cylindrical components leads to partial and ultimately to the total loss of its functional properties. In order to recreate the usable properties, a set of corrective actions, called service, is performed. Service is also understood as a set of preventive and preventive actions whose task is to maintain the usable properties of a given machine [8].

This article presents the service process and analysis of the reliability of road rollers used in the example Polish road construction company (hereinafter referred to as the company).

\section{ROAD ROLLERS SERVICE PLAN}

Road rollers consist of several basic components, which include [3]:

- drive system,

- steering system,

- rollers suspension system,

- hydraulic installation,

- water installation.

Each of these systems requires firstly preventive and preventive maintenance, and in the case of a breakdown, repairs. In the case of road machines (and not only), an important element of service is also keeping them clean and ready for use.

In the selected company it was assumed that the technical service (OT) of all vehicles will be carried out depending on the index of the review date or at a given mileage, whichever comes first. Technical service marked as OT-1 has a smaller scope, which includes activities that are collected in Table 1. In Table 2, the scope of OT-2 maintenance activities is characterized, which is characterized by a wide scope of service carried out.

\section{ANALYSIS OF THE RELIABILITY OF ROAD ROLLERS}

Six selected (representative) types of road rollers used in the company were analyzed for the failure rate. Basic information about them is presented in Tabele 3. Four of them are double-shaft steel rollers and the other two are pneumatic ones. Five of them were produced in 2005-2008, and one in 1996.

The company maintains written documentation (in the form of a "periodic service indicator"), which contains information on the type of OT carried or repair. Table 4 presents, as an example, the information about the type of service and components that were subject to it for the Dynapac CC524HF double shaft steel roller shown in Figure 1. 
Table 1

Scope of the technical inspection OT-1

\begin{tabular}{ll}
\hline \multicolumn{1}{c}{ Description } & \multicolumn{1}{c}{ Scope } \\
\hline The review is made on the basis of the review deadline & - replacement of the oil filter, \\
indicator. Transport units every $15,000 \mathrm{~km}, 20$ thousand & - replacement of engine oil, \\
$\mathrm{km}$ or every 12 months, 24 months depending on the & - checking the battery, \\
model. Technical service is carried out in accordance with & - cleaning the air conditioning, \\
the manufacturer's instructions, which are contained in & - resetting the display of the inspection intervals (maintenance indicator), \\
the service overview book. & - entering the next inspection date in the service overview book. \\
\hline
\end{tabular}

Table 2

Scope of the technical inspection OT-2

\begin{tabular}{|c|c|}
\hline Description & Scope \\
\hline $\begin{array}{l}\text { Inspection carried out in } \\
\text { accordance with the } \\
\text { service overview book } \\
\text { every } 30,000 \text { km or every } \\
24 \text { months. Technical } \\
\text { service is carried out in } \\
\text { accordance with the } \\
\text { manufacturer's instruc- } \\
\text { tions, which are conta- } \\
\text { ined in the service ove- } \\
\text { rview book. }\end{array}$ & $\begin{array}{l}\text { - replacement of the oil filter, fuel filter and/or filter cartridge, } \\
\text { - replacement of engine oil, } \\
\text { - replacing the air filter cartridge and cleaning the housing, } \\
\text { - checking the battery, } \\
\text { - checking the tightness, damage and fixing of the exhaust system, } \\
\text { - checking the oil level, } \\
\text { - replacement of engine oil and oil filter, } \\
\text { - checking glow plugs, } \\
\text { - checking operation of front lighting, rear lighting, direction indicators and hazard lights, as well as flashing } \\
\text { - warning lights, } \\
\text { - checking the condition of the v-belt driving individual components of the machine, } \\
\text { - checking the level and density of the coolant, if necessary topping up the fluid, } \\
\text { - visually checking the tightness and damage of the hydraulic transmission to the front and rear drive, } \\
\text { - checking visually tightness and damage to the engine and components in the engine compartment (from } \\
\text { the top), } \\
\text { - checking the operation and damage of the window cleaning device and if necessary topping up the liquid, } \\
\text { - checking the position of the headlights, } \\
\text { - lubrication of door stops, } \\
\text { - visually checking the anti-corrosion protection of the chassis due to damage, } \\
\text { - checking damage to the body and paint, } \\
\text { - resetting the display of the inspection intervals (maintenance indicator), } \\
\text { - entering the next inspection date in the service overview book. }\end{array}$ \\
\hline
\end{tabular}

Table 3

Characteristics of rolls used in the company

\begin{tabular}{cccc}
\hline No. & Year & Counter status/date of reading & Machine type \\
\hline 1 & 2008 & $2998 / 13.01 .15$ & DYNAPACK CC524HF \\
2 & 2008 & $2594 / 10.07 .14$ & AMMANN AP240 \\
3 & 2006 & $6380 / 09.03 .16$ & DYNAPACK CC232HF \\
4 & 2006 & $6411 / 18.04 .16$ & DYNAPACK CC522HF \\
5 & 2005 & $9277 / 21.03 .16$ & HAMM HDO-90 V \\
6 & 1996 & $3388 / 30.10 .12$ & VP-200 STAVOSTROJ \\
\hline
\end{tabular}

List of service types in the Dynapac CC524HF double-shaft road roller in years 2010-2015

\begin{tabular}{ccl}
\hline Date & Counter status in mth & \multicolumn{1}{c}{ Type of service } \\
\hline 13.01 .10 & 441 & OT-1 (engine) \\
06.12 .10 & 759 & OT-2 (engine) \\
15.11 .11$. & 1108 & OT-1 (engine + drums) \\
16.10 .12 & 1430 & OT-2 (engine) \\
06.03 .13 & 1618 & OT-1 (engine) \\
16.09 .13 & 2198 & OT-2 (engine) \\
17.10 .14 & 2930 & OT-2 (engine) \\
13.01 .15 & 2998 & Oil and hydraulic filter replacement \\
\hline
\end{tabular}




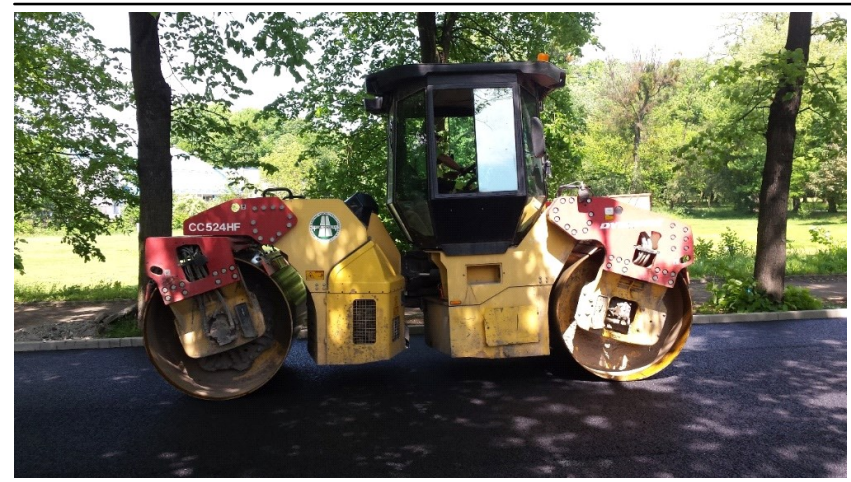

Fig. 1 Two-shaft road roller type Dynapac CC524HF Source: Own photo.

The names "engine" or "drums" mean that the service was carried out in accordance with the scope (Table 1 or Table 2) only for these roller subassemblies.

The durability and reliability of machines are different concepts, but there is a dependency between them. The reliability of an object is understood as the probability of the object meeting its requirements [6]. On the other hand, durability is one of the measures of reliability, referring to the time corresponding to reaching the value of wear after which the object has to be taken out of service [4]. It is undeniable, however, that unwanted events during operation will be less using the so-called operational thinking [5].

As mentioned earlier, the company has adopted the most popular machine maintenance system, i.e. related to time, number of kilometers driven or work hours. It should be emphasized that the adopted OT system first puts the so -called preventive prevention [5]. The anticipated scope of prophylaxis is to ensure the maintenance of a high level of reliability of road machines.

The reliability of a technical facility, understood as the ability to meet the requirements set for it, can be measured by the value of readiness factor $A$, the operational readiness factor $A_{e}$ and the preparedness coefficient $A_{u}$ [2]. When considering the reliability analysis of road rollers working in a selected road works company, we are dealing with a renewal process with a finite renewal time, including a standstill. Therefore, the rolls could be in one of four states in the operation process, namely:

- work,

- repair,

- stoppage (waiting for work),

- waiting for repair.

The operating status called waiting for repair is understood as the waiting time for the relevant parts for this repair.

The procedure for conducting reliability analysis for rollers consisted of from the following stages:

1. Acquiring data from a selected company such as:

- stop times,

- waiting times for repair,

- working times,

- repair times,

- time of emergence of damage,

- the amount of damage,

- times of commencement of the technical process.

At the same time the time of finding a defect is the time counted from the moment of damage occurrence, in a given element, until the moment when this element prevents further operation of the machine.
2. Testing the randomness of samples using a medianbased series analysis (each trial must be random).

3. Searching for differing details in tests.

4. Determination of statistical values of the reliability analysis:

- statistical parameters: average times and standard deviations of times: standstill, repair, work,

- probability distribution of the data received,

- readiness factor,

- operational readiness factor,

- contract readiness factor.

5. Evaluation of the obtained data.

Below is the determination of the three previously mentioned reliability measures for the Dynapac CC524HF roller. The readiness coefficients were determined in the same way for each road roller. The following data was obtained from the company for the Dynapac CC524HF roller:

- working time $-T_{p}=15000 \mathrm{~min}$,

- repair time $-T_{n}=480 \mathrm{~min}$,

- stop time $-T_{i}=150$ min.

Then the following statistical data were determined:

- standard deviation of working time $S_{p}=2400 \mathrm{~min}$,

- standard deviation of the repair time $S_{n}=95 \mathrm{~min}$,

- standard deviation of the stop time $S_{i}=130 \mathrm{~min}$,

- conditional waiting time for the unit to be repaired $\mathrm{T}_{\text {war }}=150 \mathrm{~min}$,

- frequency of occurrence of the waiting condition for repair $\mathrm{v}=17.8$.

The readiness factor was calculated first [1]:

$$
A=\frac{T_{p}}{T_{p}+T_{n}}=\frac{15000}{15000+480}=0.969
$$

where:

A - readiness factor,

$\mathrm{T}_{\mathrm{p}}$ - average unit work time,

$\mathrm{T}_{\mathrm{n}}$ - average unit repair time.

On the other hand, the operational readiness coefficient, taking into account the state of waiting for repair was [1]:

$$
A_{e}=\frac{T_{p}}{T_{p}+T_{n}+\frac{T_{i}}{v}}=\frac{15000}{15000+480+\frac{150}{17.8}}=0.968
$$

where:

$A_{e}$ - operational readiness factor,

$T_{i}$ - average time of unit waiting for repair,

$v-$ frequency of the waiting condition for repair.

Finally, a contractual readiness factor has been set which can be adopted when the time of delivery of spare parts is known:

$$
A_{u}=\frac{T_{p}}{T_{p}+T_{n}+\frac{T_{\text {war }}}{v}}=\frac{15000}{15000+480+\frac{2250}{17.8}}=0.961
$$

where:

$A_{u}$ - contractual factor of readiness,

$\mathrm{T}_{\text {war }}$ - conditional waiting time of the unit for repair,

$v-$ frequency of the waiting condition for repair.

In Table 5 summarizes the determined readiness rates for the six analyzed road rollers.

Five of the analyzed rolls were produced in a narrow range of years covering the period 2005-2008. 
Table 5

Ready rates for road rollers

\begin{tabular}{ccccccc}
\hline No. & Year & Counter status for a year & Machine type & $\mathbf{A}$ & $\mathbf{A}_{\mathbf{e}}$ & $\mathbf{A}_{u}$ \\
\hline 1 & 2008 & $2998 / 13.01 .15$ & DYNAPACK CC524HF & 0.969 & 0.968 & 0.961 \\
2 & 2008 & $2594 / 10.07 .14$ & AMMANN AP240 & 0.972 & 0.972 & 0.963 \\
3 & 2006 & $6380 / 09.03 .16$ & DYNAPACK CC232HF & 0.972 & 0.972 & 0.966 \\
4 & 2006 & $6411 / 18.04 .16$ & DYNAPACK CC522HF & 0.969 & 0.969 & 0.961 \\
5 & 2005 & $9277 / 21.03 .16$ & HAMM HD-90 V & 0.968 & 0.967 & 0.961 \\
6 & 1996 & $3388 / 30.10 .12$ & VP-200 STAVOSTROJ & 0.978 & 0.978 & 0.972 \\
\hline
\end{tabular}

The oldest machine, subject to analysis, is the road roller VP-200 STAVOSTROJ of Czech Republic production. Each of the analyzed rolls showed a high readiness coefficient. It is reasonable to say that road rollers used in the enterprise belong to machines with high reliability. Differences between the readiness rate, the operational ratio, or the contractual readiness factor for the same cylinder are negligible, which means that in the company the service organization and delivery of parts are carried out without unnecessary delay.

Analyzing data on OT road rollers that are in the equipment of the company, it can be stated that road rollers were subject to periodic (or related to working hours) service. Almost always OT was performed, designated OT-2, which was carried out for a longer period of time but had a wide range of maintenance activities. Therefore, mainly exploitation elements, i.e. filters, oils, etc. were replaced or controlled.

The calculated readiness coefficient for road rollers, which is close to the readiness rate, indicates that the company pays a lot of attention to a good supply of the repair workshop in order to shorten the waiting time for maintenance to a minimum. The influence of the relevant maintenance staff is probably not without significance here. You can finally be tempted to say that the planned, reliably carried out OT affects the increase of reliability of the road rollers being exploited.

The VP-200 STAVOSTROJ road roller had the highest rate of readiness from all analyzed machines. It was produced and put into operation in 1996. It has been operated by the company for over 20 years. Analyzing its periodic service control (not included in this paper) it can be stated that only OT-2 was carried out in relation to it. There was no failure. This confirms the same as previously stated that the performance of preventive and preventive activities affects in the first place high readiness for work and in the other for its durability.

The high durability of the road rollers, obviously properly serviced within one company, fully justifies the purchase of a new machine, as it can be used for a significant period of time.

\section{SUMMARY}

Road rollers are renewable technical facilities due to the possibility of repairs and replacement of elements included in their construction. Machines for compacting the bituminous mixture may be in various states defined as: working time, repair time, waiting time and waiting for repair.

In determining the reliability of the rollers, the basic parameters such as: standard deviation of the work-free time and the total working time were determined first. Next, a reliability analysis was performed, which was based on the determination of such coefficients as: readiness coefficient, operational readiness coefficient and contractual readiness ratio.

Analyzed road rollers working in a selected roadworks company were serviced several times. The most frequently replaced were various filters: fuel, air, oil and cabin equipment items. The following oils were also replaced during the inspection: engine and hydraulic.

Taking into account the reliability analysis of selected steel or rubber rollers, it was found that a selected road construction company purchased a suitable machine for performing works related to road construction. The models of road rollers considered are machines that during their operation did not suffer any serious damage, the stops in their work resulted mainly from the need for periodic inspections as well as the waiting for spare parts that were not in the repair workshop. In terms of repair time, it was found that the selected road construction company employs qualified staff whose work is organized and thought out. All the features mentioned above make the work of a steel and rubber roll profitable for the enterprise, and it does not need to be replaced with another model.

Good and well thought-out work organization, as well as quick detection and removal of damage, improve reliability. When replacing damaged parts, it is important to provide a good repair shop for shortening to a minimum of waiting time for repair. Every break in work cumulates financial losses for the company that purchased the machine as well as downtime during the entire road construction process. The increase in the reliability coefficient, as already mentioned, is facilitated by qualified service, which reduces the probability of error during operation. Therefore, companies with road rollers in their machine park should carry out periodic operator training for operators and methods of maintenance during maintenance for this machine.

Another element improving the reliability of road rollers there are innovative construction solutions that help increase comfort, safety and speed of road works. One of these solutions is the use of a hinged joint in the middle of the cylinder, which allows to reduce the turning radius. Another example is the incorporation of the latest generation of liquid crystal screens, on which basic information about the waltz's work appears. This helps to react quickly when technical problems occur [1]. The goal of all these operations is to improve the machine's operation and improve its reliability. 


\section{REFERENCES}

[1] K. Brodacki. Analysis of reliability of Dynapac CC524HF double-shaft steel road roll, Engineering project, Gliwice: Silesian University of Technology, 2017.

[2] J.M. Czaplicki. Reliability in the mechanization of mining and diggingworks, Gliwice: Publisher of the Silesian University of Technology, 2012.

[3] M. Jodłowski. Operator of machines for road works, Krosno: KaBe Publishing, 2009.

[4] S. Legutko. The basics of exploitation of machines and devices, Warsaw: School and Pedagogic Publishing, 2004.

dr inż. Michał Stawowiak, dr inż. Mariusz Kuczaj

Silesian University of Technology

Faculty of Mining and Geology

Department of Mining Mechanization and Robotisation

ul. Akademicka 2, 44-100 Gliwice, POLAND

e-mail: michal.stawowiak@polsl.pl

mariusz.kuczaj@polsl.pl
[5] J. Lewitowicz, A. Żyluk. The basics of aircraft operation. Technical operation of aircraft, Warsaw: Publisher of the Technical Institute of Air Force, 2009.

[6] E. Macha: "Machine reliability”. Scientific Scripts of the Opole University of Technology, vol. 237, 2001, pp. 13-17.

[7] J. Napiorkowski, P. Drożyner, P. Mikołajczak, A. Rychlik, P. Szczyglak, K. Ligier. Basics of construction and operation of vehicles and machines, Olsztyn: EXPOL Publishing, 2013.

[8] T. Żuk. The basics of exploitation of machines and devices house, Warsaw: Publisher of Warsaw University of Technology, 1984. 